\title{
Introduction to Knowledge Society, Culture, and Information Systems Minitrack
}

\author{
Dave T. Croasdell \\ University of Nevada, Reno \\ Davec@unr.edu
}

\author{
Minna Rollins \\ University of West Georgia \\ mrollins@westga.edu \\ Nilmini Wickramasinghe \\ Deakin University \\ n.wickramasinghe@deakin.edu.au
}

\author{
Mika Gabrielsson \\ University of Eastern Finland \\ mika.gabrielsson@uef.fi
}

Our minitrack focuses on various cultural aspects of Knowledge Management and Information Systems within organizations. First two papers in our minitrack investigate cross-cultural issues and challenges in managing knowledge within a global firm. The first paper of in this minitrack by Frygell, Hedman, and Carlsson, "Implementing CRM System in a Global Organization National vs. Organizational Culture" study Customer Relationship Management (CRM) implementation in China, Poland, Russia, Middle East, Dubai, Pakistan, Iran, Korea and Japan within one global company. Frygell et al. conclude that implementation of CRM was not a complete success. Based on their findings from longitudinal case study, authors emphasize the importance of understanding the difference between the organizational culture in which the CRM system is developed and the national culture in which the system is implemented. The second paper “International Firms' Market Orientation and Use of Knowledge: Implications for Market Information Systems" by Pehrsson explores market orientation in international industrial firms. Pehrsson states that "an understanding of the importance of knowledge of foreign markets and use situations will facilitate the design of market information systems that include creation and sharing of knowledge within international industrial firms."

Next two papers explore the impact of organizational culture on Information Systems implementation and use. The third paper of the minitrack, "ComputerSupported Knowledge Management in SME - A Combined Qualitative Analysis" by Kramer, Jamous, Becker, Wirth, Klingner, Friedrich, and Schneider investigates the current state of the art on computer based Knowledge Management Systems (KMS) and commercial Knowledge Management (KM) tools. Authors explain that recent SME-related KM tools do not address $\mathrm{KM}$ in a holistic managerial way. For instance, KMS fail to link operative data sources such as ERP and CRM, lack effective reward and enabling processes to more quickly establish a knowledge sharing culture among employees. Our fourth paper is titled "How Individual Technology Propensities and Organizational Culture Influence B2B Customer's Behavioral Intention to Use Digital Services at Work?". Hallikainen, Paesbrugghe, Laukkanen, Rangarajan, and Gabrielsson examine how individuals' technology readiness in conjunction with organizational culture impacts on business-to-business customers' behavioral intention toward using digital services in their procurement processes.

Academic disciplines form their own knowledge cultures. The last paper of the mini-track "A Look into the IS Discipline through the Lens of MIS Quarterly: A Visual Examination of Scholar Characteristics" by LaBrie and Anantha investigate the characteristics of knowledge creators by investigating a subset of information systems (IS) researchers who have published in MIS Quarterly. Findings suggest an increase of women, international scholars, and locations over time, are adding to the richness and diversity of the IS field.

Last, we want to thank all authors and reviewers. 